\title{
Hydrogen city
}

\author{
C. Jefferson ${ }^{1,2} \&$ J. Skinner ${ }^{2}$ \\ ${ }^{1}$ Faculty of Computing, Engineering and Mathematical Sciences, \\ University of the West of England, Bristol, UK \\ ${ }^{2}$ Sustraco Ltd, UK
}

\begin{abstract}
It has been predicted that by the year 2020 the demand for oil and gas will outstrip supply, which is bound to force up prices. At that stage hydrogen will become increasingly important in filling the gap. The market for hydrogen will expand to meet increasing demand. The quest to reduce $\mathrm{CO}_{2}$ emissions will accelerate this demand. Fifteen years is a short time in which to prepare for the change. Many commentators consider we will reach this point sooner while some say we have already reached it. This matter will strongly influence the criteria for sustainability in urban planning and development. This paper seeks to show how innovative transport planning can contribute to sustainability rather than detract from it.
\end{abstract}

\section{Objectives of a carbon free city}

The objectives in planning a carbon free city can be summarised thus:

- Provision of sufficient affordable housing

- Energy self sufficiency

- Zero net carbon emissions

- Car free mobility and accessibility

- A safe and healthy environment

\section{Aims of planning policy}

- To provide compact neighbourhoods of up to 2000 dwellings, of which $30 \%$ would be low cost dwellings with low or zero private car dependence, with community based energy supply and good access to open space. 
- To provide local amenities and effective collective transport to reduce the need for car journeys.

- $\quad$ To minimise waste by use of existing infrastructure where appropriate and by maximised provision of recycling facilities

- To maximise energy efficiency throughout the development, including transport.

- To use hydrogen generated from renewable sources to displace carbon based fuels as far as possible.

In summary, to achieve genuine sustainable carbon neutral development and urban regeneration by integrated land use, energy and transport planning.

\section{Urban design}

With growing population and decreasing land availability it makes obvious sense to plan for high-density development in urban areas. High-density urban planning is more difficult for planners and architects to design successfully than low-density suburban sprawl. But, where it is well done, it can produce the most popular forms of human habitation, whilst minimising the cost of energy and other municipal services. All around the world, it is in the crowded ports and hill towns, where limited space has made high-density development unavoidable, that the best architecture and the most creative urban design are to be found. These are now the places which have become the tourist hot-spots with the highest land values.

Today, in large buildings, lifts provide zero emission mobility between floors while solar energy powers the air conditioning. We can extend this idea to a whole city region. Residential, commercial, governmental and recreational development can be planned so that they are connected by permanent transit systems, to each other and to transport interchanges such as railway stations, airports and park-and-ride sites.

Clean, cheap, attractive and efficient urban transport is an essential and integral component of any successful urban design. The planning of access routes and public transport systems in urban areas is so often treated as an afterthought, to be added on or inserted into the main body of the design instead of being incorporated into the plans at the very beginning. Planning should be based around the arteries which will enable the whole community to move freely and safely. Effective public transport systems are as essential to successful urban development as lifts are to tall buildings.

The capital cost of installing such citywide public transport systems should be considered an integral part of the overall funding of any urban development scheme - as fundamental to its success as the provision of efficient plumbing, heating and electricity. 


\section{The urban transport crisis}

Urban transport systems all over the world are in crisis. Congestion is damaging both the economy and the quality of life, particularly in urban areas, whilst pollution is killing people and hastening global warming. There is an urgent need to bring about radical changes in urban transport and development to overcome these problems. The principle, over-riding task is to find ways of phasing out our present dependence on fossil fuels. This will be a massive task and we need to start planning for it now. The fossil fuel market is already highly volatile, but over the next few decades it is likely to become increasingly difficult to ensure steady supplies of fossil fuel products at stable, affordable prices. Ultimately, as finite resources dwindle to uneconomic levels, we shall have to rely exclusively on alternative sources of energy, which will need to be renewable. Because this change will be so radical and far-reaching it will take many years to plan and implement. But we have only limited time.

Even if resources of fossil fuels were unlimited, pollution alone would provide more than sufficient reason to phase out their use, especially in urban areas, where pollution causes premature mortality $(24,000$ p.a. in the UK). Global warming has added yet another even more urgent reason for action. Therefore the three over-riding strategic considerations, within which urban planning and sustainable development must be conducted, are namely -

- $\quad$ energy security - reducing and ultimately eliminating our dependence on fossil fuels

- $\quad$ public health - reducing and ultimately eliminating toxic emissions from transport

- climate change - reducing and ultimately eliminating net carbon emissions

These strategic considerations need to be incorporated into any overall strategy in order to create the sustainable towns and cities of the future. The following section describes how such sustainable urban development could take place.

\section{Principles of planning for urban sustainability}

Warren [1] has proposed 'urban oases' comprising mixed use landscaped communities in which all buildings are within 5 minutes walking distance of an efficient central public transport facility and local amenities, from which pedestrian and cycle routes radiate. The area would be largely car free, apart from traffic calmed roads around the perimeter for servicing and to provide access to parking provision for no more than half the residents. Further parking would be available at sites accessible by the public transport system. Figure 1 shows how such a community might be planned.

Such 'oases' could be linked with shared ameneties such as libraries, clinics, schools etc which could be distributed around a linear or circular transit route, interconnecting with the main railway station as in figure 2 . Such clusters will 
be referred to as urban areas and will effectively be self contained towns in their own right. This arrangement is described by Barton et al [2] as a way of shaping sustainable neighbourhoods.

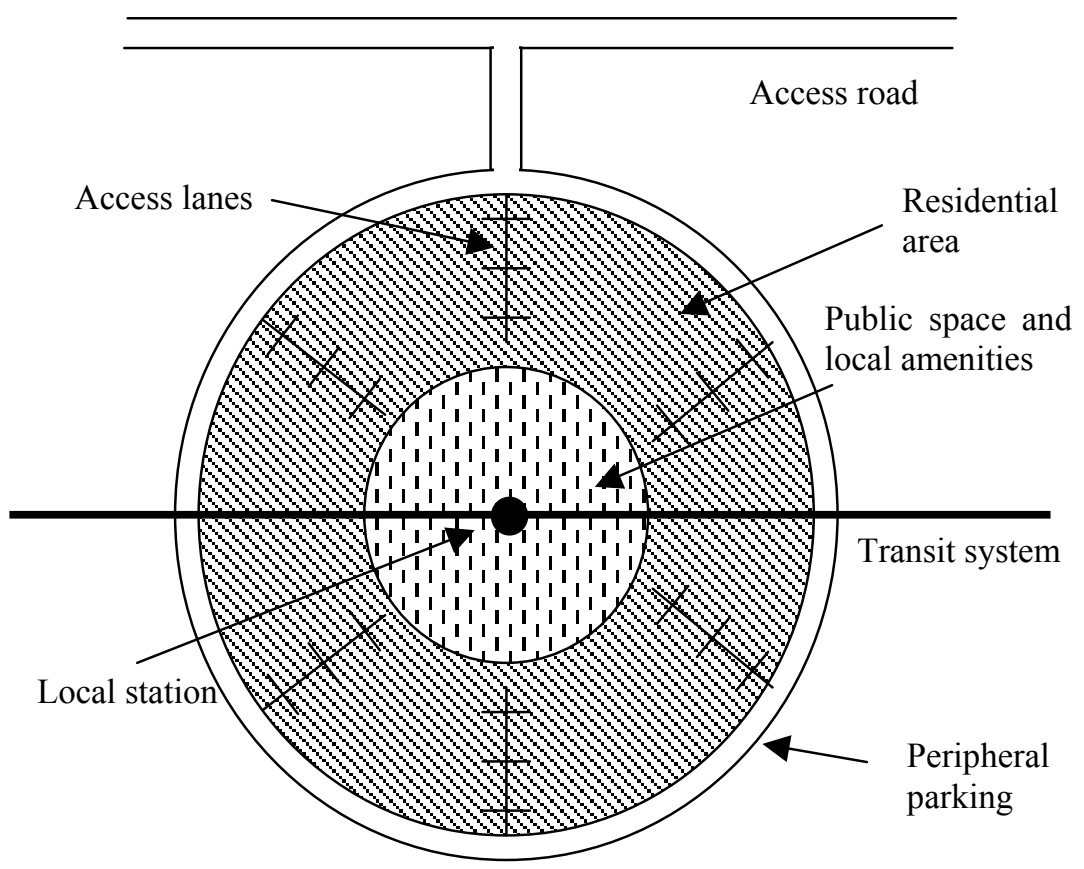

Figure 1: Plan for urban community.

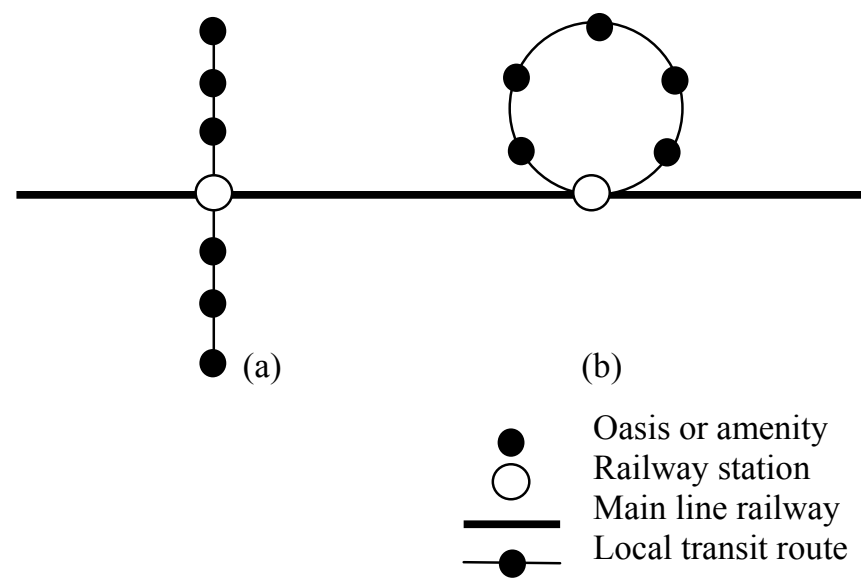

Figure 2: Optional distribution of oases and amenities in 'towns'. 


\section{Urban mobility planning}

\subsection{Planning objectives}

To provide high-density urban developments, with extensive pedestrianised areas and clean, quiet, quick, safe, energy efficient mobility services. These services should be designed to meet public transport needs, in sustainable ways, by providing generally acceptable alternatives to private cars. Pollution and carbon emissions due to transport should be minimised and public transport easily available to everyone - both able and disabled.

\subsection{Walking}

Urban design should be based on the principle that each individual should have maximum opportunity for safe and undisturbed access to goods and services, recreational, educational, commercial and Governmental facilities by walking or, for longer distances, by public transport.

\subsection{Cycling}

Adequate provision throughout urban areas should be made for cycle paths, which provide cyclists with freedom of movement without threat to pedestrians or to themselves. The cycle paths need therefore to be segregated from pedestrians in busy areas and, as far as possible, from other modes of transport.

\subsection{Access routes: zero-emission electric mopeds, minibuses, rickshaws, buggies and taxis}

Adequate provision should be made for these alternative modes of clean public and private transport to operate in designated shared space throughout the urban area, where they do not threaten pedestrians or each other and have easy access to attractive interchanges with other modes of local and inter-urban transport.

\subsection{Public transport provision}

A comprehensive public transport system should provide the main arteries of the body of the urban area, as shown as the transit routes in figure 2 . The system may run from the centre to park-and-ride facilities on the periphery (figure 2a). Easy interchange with the main-line railway station and possibly with other transit routes, as well as connections with private vehicles and taxis, need to be allowed for at intersections. The system must be able to run through open and covered pedestrian areas, at 2-3 minute intervals, without threatening the health or safety of people using those areas. Trams have traditionally served such areas well. However, while the system should be segregated where appropriate, trams, unlike buses, have the advantage that they can provide unobtrusive access to pedestrian central areas and parks. 


\subsection{The vehicles}

In order to make economic use of the hydrogen fuel, all vehicles must be designed for maximum energy efficiency. Vehicles with steel wheels running on steel rails have reduced rolling resistance and thereby have improved energy efficiency over rubber tyred vehicles. This singles out the tram, which has already gained worldwide acceptance and popularity.

\subsection{Park-and-ride}

Private cars should be provided with parking space in covered park-and-ride facilities at the urban periphery (figure 1), where connections with pedestrian routes and all kinds of enhanced urban mobility systems are easily and frequently available. These facilities could be built under cover, with vegetation growing on top. The costs of constructing park-and-ride interchanges that are unobtrusive and attractive can be met by leasing commercial facilities to take advantage of the activity generated by the interchange. By concentrating parking on the urban periphery, higher value land in the centre can be made available for development and provision of amenities, instead of being used for parking. Such development could be car and pollution free and genuinely sustainable.

\subsection{Freight and goods transport}

Freight distribution centres should be developed in association with park-andride sites and main-line railway stations. Goods can then be distributed within urban areas by more appropriate vehicles than those used for inter-city transport. The light rail infrastructure can be used during off-peak hours for the collection of waste and the distribution of heavier goods, whilst small and medium sized electric vans can be used for other items.

\section{Why hydrogen?}

In the interest of reducing emissions, including $\mathrm{CO}_{2}$, fossil fuels should be excluded from use in urban areas. Hydrogen can be used to produce entirely emission free energy for domestic, industrial and transport use. Local fuel cell combined heat and power schemes can produce heat and electrical power with high efficiency free from all emissions, including noise and $\mathrm{CO}_{2}$. There appears to be a growing consensus that hydrogen will become the principle replacement for fossil fuels, providing the major new energy currency to be used in dealing with future energy demand. This is because hydrogen is not just a fuel but a means of storing electrical energy, which can be generated from any kind of renewable source. Local power generation from renewable sources such as wind, sewage and waste can be used to produce hydrogen in situ to save unnecessary costs in the distribution of fuel and electricity. Hydrogen provides a valuable opportunity for large- scale local energy storage for domestic and transport use. Energy storage capacity is vitally important to the future supply of electricity. 
Hydrogen production by electrolysis can take place at off-peak times when electricity exceeds the demand and the electrolyser forms an ideal interruptible load, enabling demand management measures and the integration of intermittent forms of renewable energy, such as wind or sun. This should result in a low tariff for electricity supply at off-peak times or at other periods of abundant supply. At times of high demand, the electrolyser load could be shed, thereby assisting in grid stabilisation and reducing supply costs.

Hydrogen fuel cell generators in hybridised drive trains will probably become the most common form of on-board power source for transport and are ideal for the proposed transit vehicles. On-board energy storage systems such as flywheels or supercapacitors can be used to recover brake energy, further improving energy efficiency. Hydrogen can thus be produced and used economically as fuel for the tram system as well as for domestic use. The present state of the technology will already allow energy efficient hydrogen fuel cell powered trams to be used for the local public transport services. The high cost of fuel cells and hydrogen is offset by the very high energy efficiency of the vehicles.

\section{Bristol, a case study}

Bristol has the potential, mainly on Severnside, to produce up to 9 GWhe/yr of hydrogen energy, without increasing carbon emission, through its renewable energy programme [3]. The potential resource in Bristol is shown in table 1. The renewable electrical power available for hydrogen production is assumed to be derived mainly from wind power as part of a load management scheme and is taken as $33 \%$ of the total resource based on the proportion of electricity available at low off-peak tariff. Hydrogen produced directly from waste is additional.

Table 1: $\quad$ Potential renewable energy resource, Bristol and Severnside.

\begin{tabular}{|l|c|c|c|c|}
\hline $\begin{array}{c}\text { Renewable } \\
\text { source }\end{array}$ & $\begin{array}{c}\text { Electrical } \\
\text { power }\end{array}$ & $\begin{array}{c}\mathrm{CO}_{2} \text { emission } \\
\text { saved }\end{array}$ & $\begin{array}{l}\text { Power } \\
\text { available for } \\
\mathrm{H}_{2} \text { production }\end{array}$ & \% \\
\hline WWhe. $\mathrm{a}$. & t.p.a. & GWhe p.a. & 28 \\
\hline CHP & 3.6 & 3000 & 3.2 & 11 \\
\hline Waste & 22 & 1200 & 1.2 & 61 \\
\hline Total & 35.3 & 6200 & 11.4 & 100 \\
\hline
\end{tabular}

*@ $0.43 \mathrm{~g} /$ Whe, the rate set by the Climate Change Levy Negotiated agreement. 


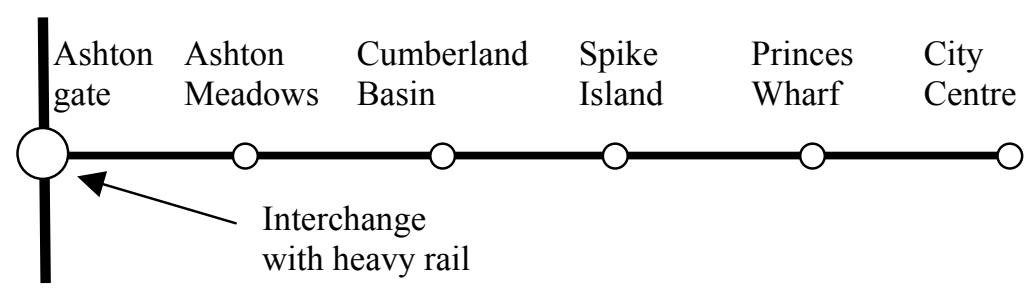

Figure 3: $\quad$ Potential transport system for Bristol carbon free development.

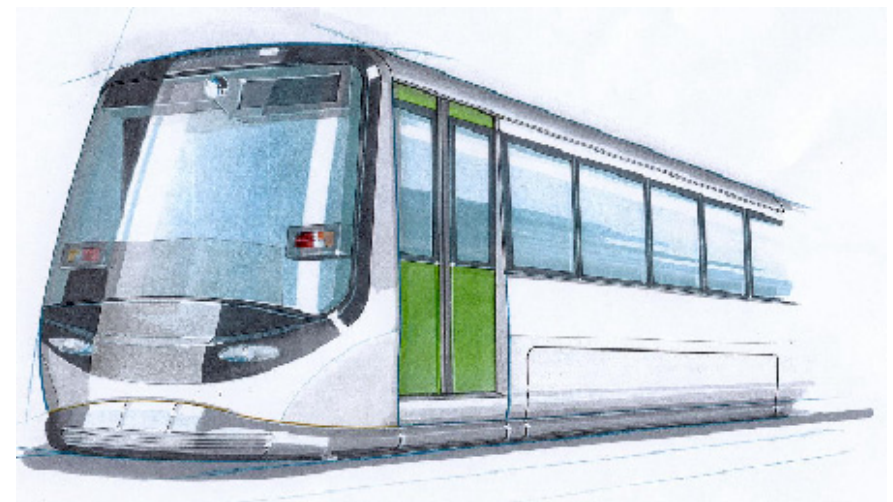

Figure 4: Impression of proposed tram.

\section{Zero emission transport}

Bristol has the advantage of a disused rail corridor between Princes Wharf, near the centre, and Ashton Gate which could, at modest cost, be developed into a light rail service connecting the Centre with Ashton Vale and beyond, as shown in figure 3. A scheme to convert this railway to a light rail service was incorporated into Bristol's local transport plan [4] and is now adopted as a component of the City Centre Strategy [5].

This route would serve the area of derelict land available for Hydrogen City and provide the pollution free alternative to car use as set out in the project aims. The light rail service would operate on the hydrogen fuel from the sources in table 1 . It is estimated that it would require only $1.2 \mathrm{GWhe} / \mathrm{yr}$ of renewable power or $38 \%$ of the available wind resource. The estimated $\mathrm{CO}_{2}$ emission saving due to reduced car use alone is expected to be 430 t.p.a.

The line connects with a proposed local suburban railway and could be extended out to the airport and beyond. At the other end it could be extended to the main rail station and shopping centre.

\section{Conclusions}

(1) There are three strategic imperatives which will inevitably have to dominate the formulation of all future transport policy and planning. These are energy 
security, public health and global warming. All of these underline the urgent need to take action now to start phasing out the present dependence on fossil fuels.

(2) Successful modernisation of urban transport needs to be carried out with the aim of assuring improvements in the overall quality of urban life by providing easy mobility, accessibility and clean air for all, regardless of income or disability.

(3) The design of modern urban development and regeneration should aim for high quality and high density, centred on public transport nodes, and aim at minimising the waste of resources and energy consumption.

(4) Energy efficiency will be the essential priority in the selection of transport modes. This means that rail-based vehicles, which are three times more energy efficient than rubber tyred vehicles, will form the basis of future urban public transport.

(5) Hydrogen will play a crucial role as the means of storing renewable energy for release in the form of electricity through fuel cells. This increases the viability of intermittent renewable energy (e.g. wind) and of hydrogen as fuel for transport.

(6) By reducing the capital cost of urban light rail systems, funding problems can be made more tractable. The capital cost of the vehicles and infrastructure can easily be offset against the land value gain. In some highdensity areas it may even make commercial sense to provide public transport services which are free.

(7) By providing tram systems which people like to use, modal shift from cars to public transport will increase, patronage and fare revenue will rise, scarce energy will be saved. Just as they provided mobility solutions for Victorian cities, trams could provide the key to future genuine sustainable development.

\section{References}

[1] Warren R 'Urban Oases, Dealing with the densities and a role for affordable APM shuttles and loops' Proc. Urban Transport and the environment, Lisbon, Sept 1998, PP 73-82.

[2] Barton H, Grant M and Guise R, Shaping Neighbourhoods, Spon Press, London 2003, pp123-127.

[3] Bristol City Council, Energy Management Update, Energy Management Unit, January 2005, pp10-11.

[4] Bristol City Council, Bristol Local Transport Plan 2001-2 - 2005/6, July 2000, pp56-58.

[5] Bristol City Council, Bristol City Centre Strategy and Area Action Plan, 2005 - 2010, section 1, November 2005, p17. 